\title{
Failure Diagnosis for Demagnetization in Interior Permanent Magnet Synchronous Motors
}

\author{
Takeo Ishikawa, Naoto Igarashi, and Nobuyuki Kurita \\ Division of Electronics and Informatics, Gunma University, 1-5-1 Tenjin-cho, Kiryu, Gunma 376-8515, Japan \\ Correspondence should be addressed to Takeo Ishikawa; ishi@gunma-u.ac.jp
}

Received 13 May 2017; Accepted 10 September 2017; Published 16 October 2017

Academic Editor: Tariq Iqbal

Copyright (C) 2017 Takeo Ishikawa et al. This is an open access article distributed under the Creative Commons Attribution License, which permits unrestricted use, distribution, and reproduction in any medium, provided the original work is properly cited.

\begin{abstract}
Since a high degree of reliability is necessary for permanent magnet synchronous motors, the detection of a precursor for the demagnetization of permanent magnets is very important. This paper investigates the diagnosis of very slight PM demagnetization. The permanent magnet volume is altered so as to mimic the effect of demagnetization. This paper investigates the influence of demagnetization by using several methods: the 3D finite element analysis (FEA) of the motor, the measurement of high-frequency impedance, and the measurement and FEA of the stator voltage and current under vector control. We have obtained the following results. The back-EMF is proportional to permanent magnet volume, and there is no difference in the demagnetization in the radial direction and in the axial direction. Even harmonics and subharmonics of flux density at the teeth tip could be useful for diagnosis if a search coil is installed there. The relatively low frequency resistance at the $d$-axis position is useful for diagnosis. Under vector control, the stator voltage is useful except in an intermediate torque range, and the intermediate torque is expressed by a simple equation.
\end{abstract}

\section{Introduction}

Permanent magnets (PMs) of permanent magnet synchronous motors (PMSMs) can be demagnetized by temperature, large stator currents, large short-circuit currents produced by the inverter or stator faults, and the aging of magnet itself. Moreover, because the PM material is often magnetized after it is inserted into the rotor assembly, there is a possibility that the PM is not in a state of complete magnetization. Since a high degree of reliability is necessary for PMSMs, the detection of a precursor to the demagnetization of PMs is very important [1].

There have been several research studies that explored methods for detecting the demagnetization of a PM. Rajagopalan et al. created a magnet defect by chipping off a part of the magnet and then measured the stator current [2]. Urresty et al. made several contributions [1,3-5]. They analyzed the stator current of a PM motor using several methods: Hilbert-Huang transform, method based on Boxcounting fractal dimension, zero-sequence voltage component, and back-EMF based method. Liu and Zhu also showed that the magnetization can be estimated from the back-EMF
[6]. Moreover, in order to determine the magnet temperature caused by the demagnetization, some approaches have been proposed [7]. One possible way to determine the rotor temperature under real-time conditions is a precise flux observer [8]. The other method is an invasive method, which estimates the impact of the flux variation on the motor's magnetic circuit from the current response to injected voltage signals $[9,10]$. However, in [1-5] the volume of the PM was decreased by $16.7 \%$. The degree of PM demagnetization in these past studies was relatively large. It would be preferable to be able to detect the onset of demagnetization to provide the user with advance notice that the magnet is beginning to be demagnetized.

Although all poles may be uniformly demagnetized owing to the causes of demagnetization described above, the previous research studies created the magnet defect by chipping off a part of the permanent magnet or by reducing the volume of only one pole. In this study, the volume of only one pole is also reduced to simulate the demagnetization. In order to deal with a less demagnetized situation compared to those in the previous research studies, the volume of one of the four PMs is reduced by $10 \%, 20 \%$, and $30 \%$; that is, 


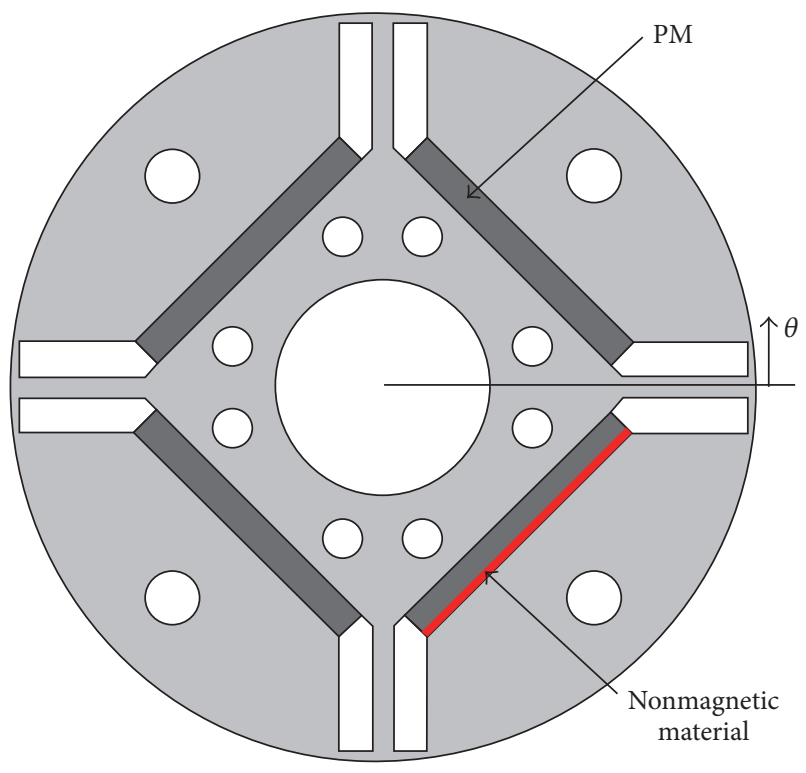

(a) Rotor configuration

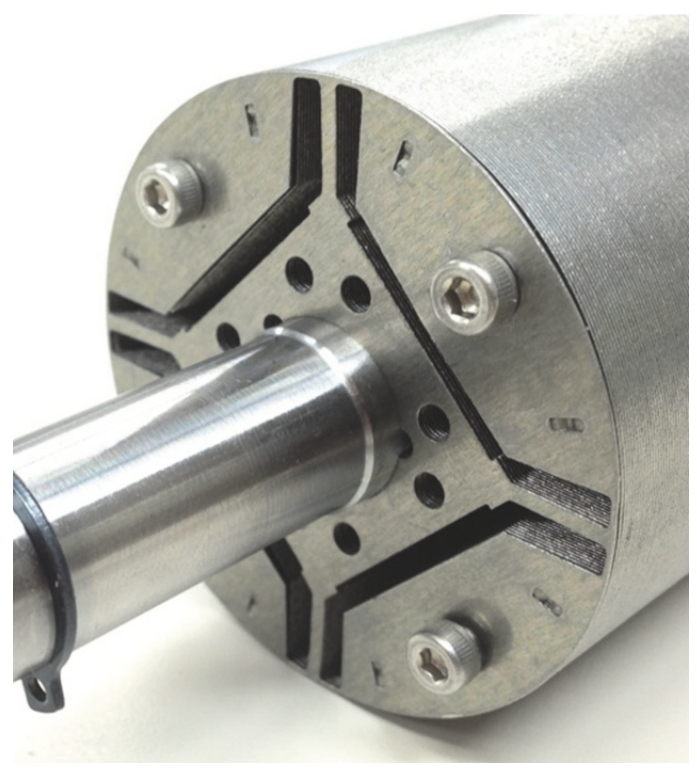

(b) Photograph of rotor

FIGURE 1: Rotor of the experimental PMSM.

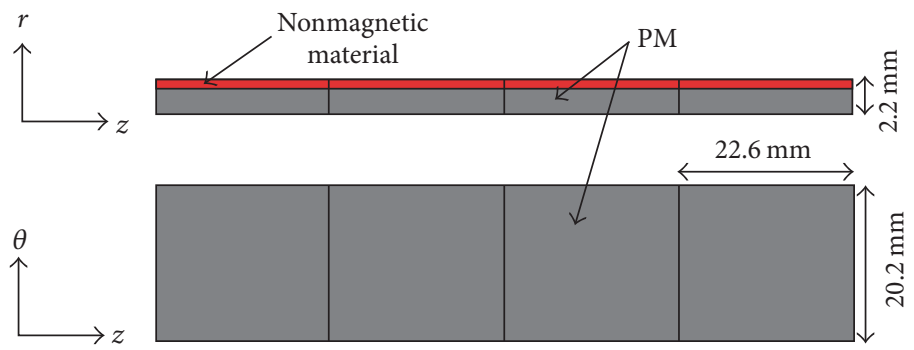

(a) Magnet configuration

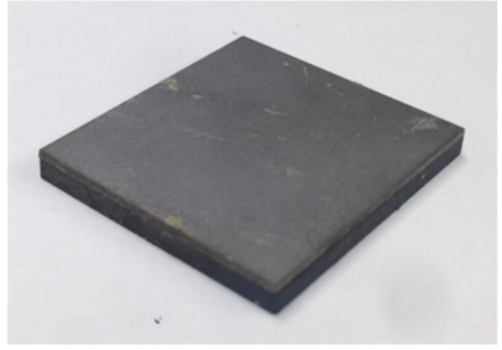

(b) Photograph of magnet

FIgURE 2: PMs for radial demagnetization.

the total volume of PM material used is decreased by $2.5 \%$, $5.0 \%$, and $7.5 \%$, respectively, in separate experiments [11]. Two types of demagnetization are taken into account, that is, demagnetization in the radial direction and axial direction.

In this paper, physical variables to be available for diagnosis for less demagnetization in interior permanent magnet synchronous motors are clarified by simulations and experiments. First, electromotive force, inductances, highfrequency impedance, and magnetic flux density in the air-gap are investigated. Next, the voltage and current are investigated when the motor is driven under a vector control strategy.

\section{Rotor Configuration of PMSM with Permanent Magnet Defect}

Figure 1(a) shows the rotor configuration of an experimental PMSM. This motor's rating is as follows: $1.5 \mathrm{~kW}, 3000 \mathrm{~min}^{-1}$, $4.8 \mathrm{~N} \mathrm{~m}, 5.6 \mathrm{~A}$, four-pole machine. The PM volume of one of four poles is altered so as to mimic the effect of demagnetization. Figure 1(b) shows a photograph of the rotor of the experimental PMSM. When performing experiments with several motors, slight differences between motors can affect the relative motor performance especially if the amount of demagnetization is small. In order to avoid this problem, we perform experiments on the same stator and the same rotor using the different PMs.

Figure 2(a) shows the demagnetization in the radial direction. We define this operating condition as radial demagnetization hereafter. One pole is composed of four PMs, and the thickness of the four PMs which compose one pole is reduced by $10 \%, 20 \%$, and $30 \%$, in separate experiments, in order to imitate demagnetization or imperfect magnetization as shown in Figure 2(b). Figure 3(a) shows the demagnetization in the axial direction. We define this operating condition as axial demagnetization hereafter. The axial length of two of the four PMs per pole is reduced by $20 \%, 40 \%$, and $60 \%$ as shown in Figure 3(b). Therefore, the PM volume of one pole for axial demagnetization is approximately the same as that for radial demagnetization. In order to remove eccentricity, nonmagnetic materials are inserted into the region where the PM is decreased. The volume of PMs is shown in Table 1. Here, 


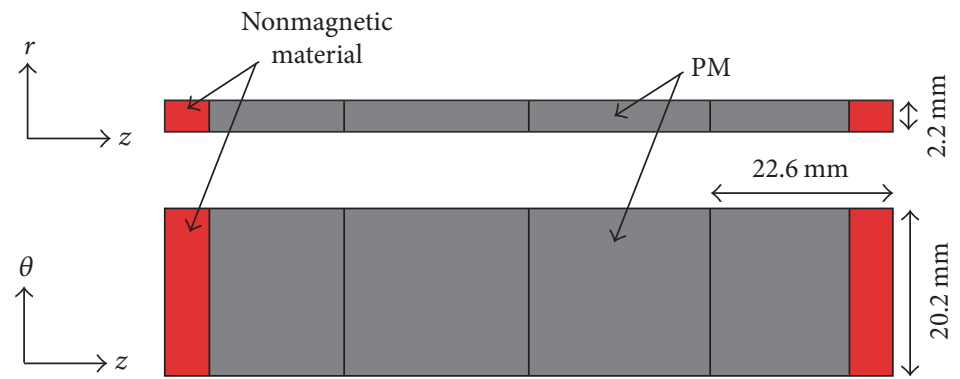

(a) Magnet configuration

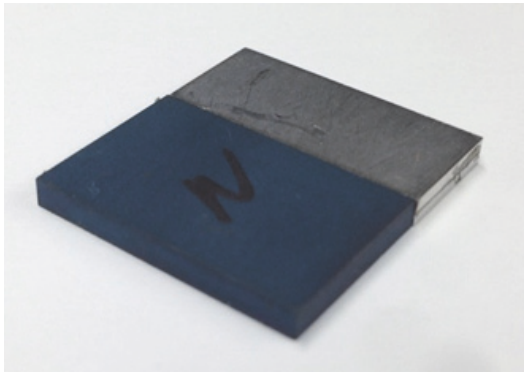

(b) Photograph of magnet

FIgURE 3: PMs for axial demagnetization.

TABLE 1: Dimension of PMs.

\begin{tabular}{lccccc}
\hline PM & $L[\mathrm{~mm}]$ & $W[\mathrm{~mm}]$ & $H[\mathrm{~mm}]$ & $V\left[\mathrm{~mm}^{3}\right]$ & 16070 \\
\hline Healthy & 22.6 & 20.2 & 2.2 & 15704 \\
$R-2.5 \%$ & 22.6 & 20.2 & 2.0 & 15339 \\
$R-5.0 \%$ & 22.6 & 20.2 & 1.8 & 14974 \\
$R-7.5 \%$ & 22.6 & 20.2 & 1.6 & 15661 & 0.977 \\
$Z-2.5 \%$ & 18.0 & 20.2 & 2.2 & 15252 & 0.955 \\
$Z-5.0 \%$ & 13.4 & 20.2 & 2.2 & 14843 \\
$Z-7.5 \%$ & 8.8 & 20.2 & 2.2 & 0.975 \\
\hline
\end{tabular}

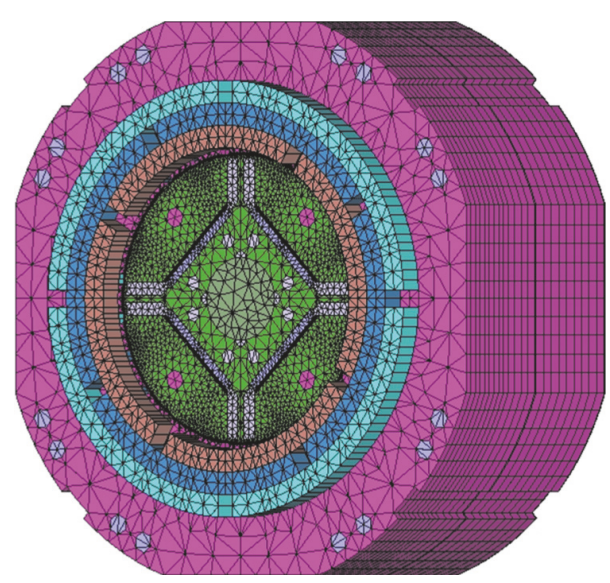

FIGURE 4: Finite element mesh for the analyzed motor with demagnetized magnet.

healthy means motor with fully magnetized PMs, $R-2.5 \%$ means motor with PMs demagnetized in the radial direction by $2.5 \%$, and $Z-2.5 \%$ means motor with PMs demagnetized in the axial direction by $2.5 \%$. PMs were manufactured by $0.1 \mathrm{~mm}$ step.

\section{Electromotive Force of Demagnetized Motor}

The flux distribution in the motor at no load is calculated using the $3 \mathrm{D}$ finite element method. The analysis model is $1 / 2$ of the model in the axial direction, because there is no symmetric condition in the circumferential direction. The numbers of nodes and elements are 132,813 and 225,758, respectively, as shown in Figure 4.
TABLE 2: Measured flux linkage.

\begin{tabular}{lcc}
\hline Motor & $\Phi[\mathrm{Wb}]$ & $\Phi / \Phi_{\text {healthy }}$ \\
\hline Healthy & 0.2157 & - \\
$R-2.5 \%$ & 0.2108 & 0.978 \\
$R-5.0 \%$ & 0.2055 & 0.954 \\
$R-7.5 \%$ & 0.2002 & 0.930 \\
$Z-2.5 \%$ & 0.2104 & 0.976 \\
$Z-5.0 \%$ & 0.2048 & 0.950 \\
$Z-7.5 \%$ & 0.1994 & 0.925 \\
\hline
\end{tabular}

Figure 5 shows the calculated electromotive force, when the motor is rotating at $1,500 \mathrm{~min}^{-1}$. It is shown that the electromotive force is proportional to the volume of PMs, and the waveform of electromotive force of the motor with radial demagnetization is the same as that of axial demagnetization. Figure 6 shows the measured electromotive force, when the motor is rotating at $1500 \mathrm{~min}^{-1}$. It is shown that the waveforms of the measured electromotive force are approximately same as the calculated ones. In order to show the difference between the demagnetized and healthy situations, Table 2 shows the flux linkage, which is the integral of the electromotive force. It is well known that the magnetization of PMs can be estimated from the back-EMF $[5,6,8]$ In this paper, it is found by both simulations and experiments that the reduction of the flux linkage of the motor with demagnetized PMs is equal to the reduction of PM volume. There is no difference in the back-EMF of the motor with PMs demagnetized in the radial direction and in the axial direction. 


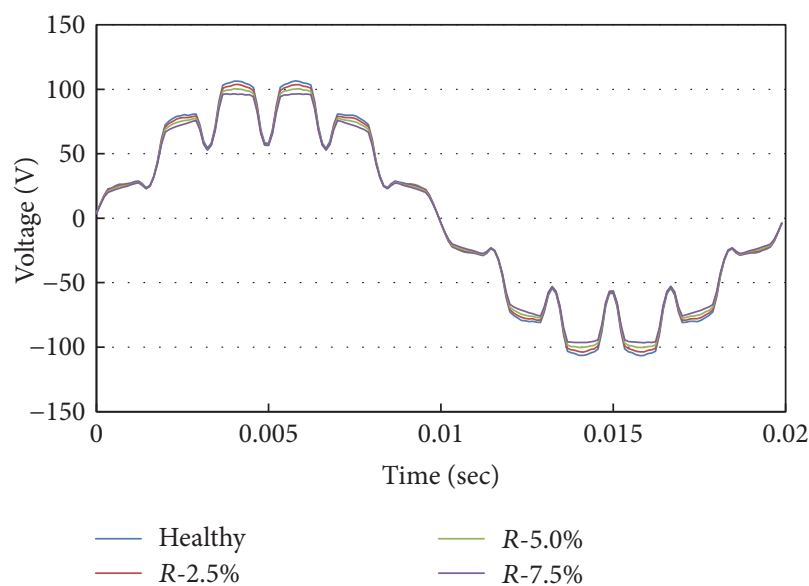

(a) Radial demagnetization

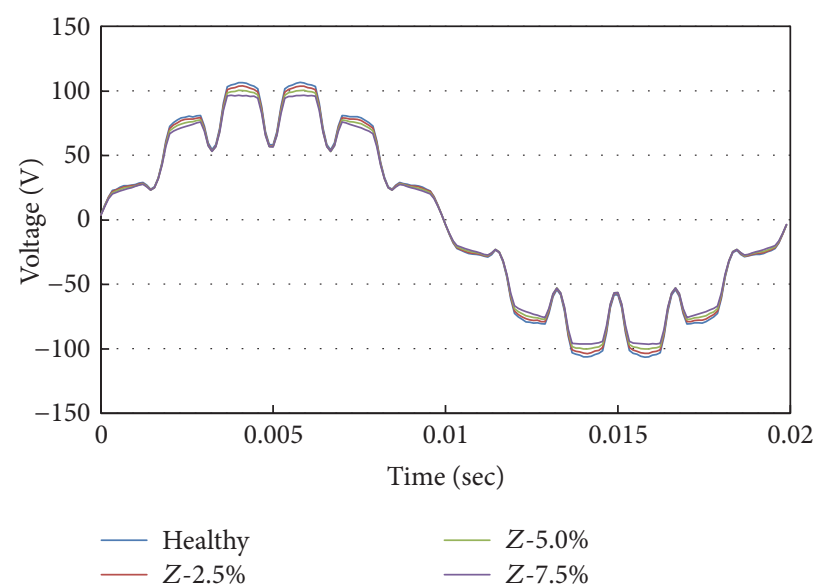

(b) Axial demagnetization

Figure 5: Calculated EMF waveform.

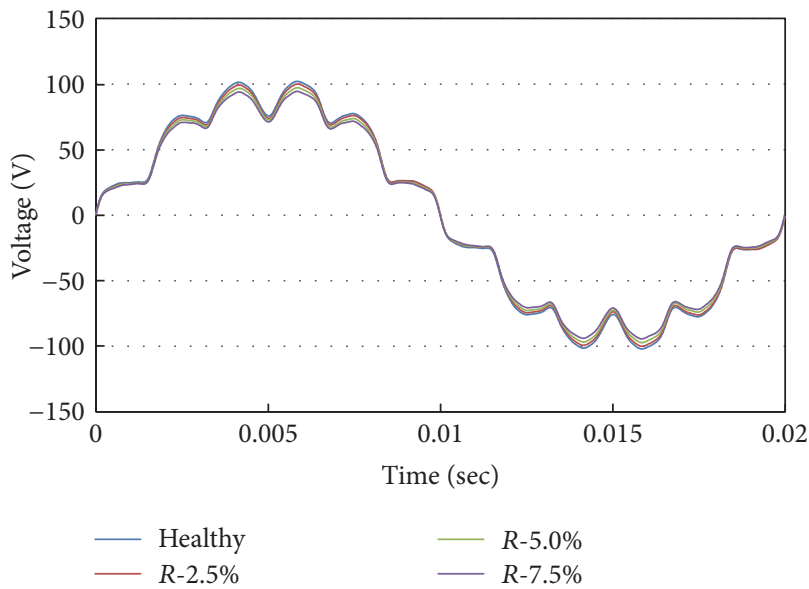

(a) Radial demagnetization

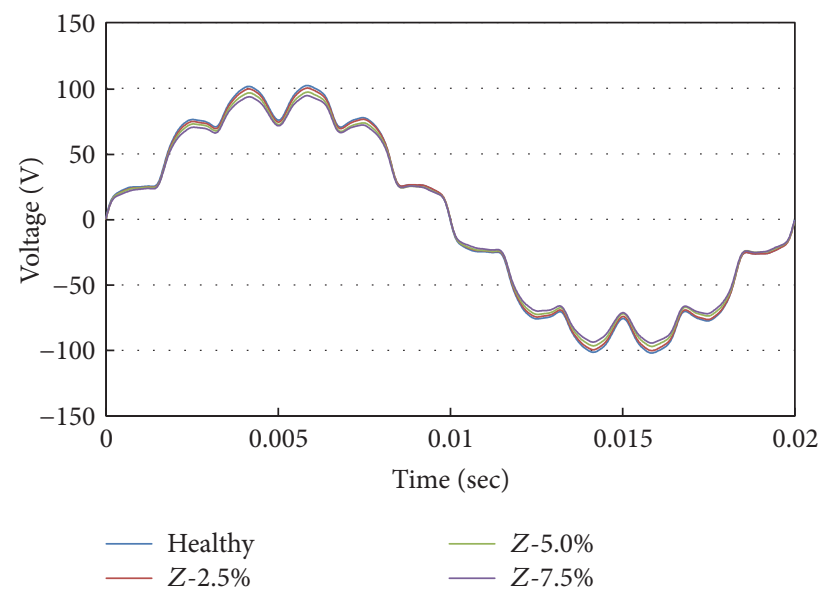

(b) Axial demagnetization

Figure 6: Measured EMF waveform.

Figure 7 shows the calculated magnetic flux density at the center of the air-gap and at the center of the axial direction. The magnetic flux density is reduced from $0.516 \mathrm{~T}$ to $0.481 \mathrm{~T}$ for the radial demagnetization and from $0.516 \mathrm{~T}$ to $0.479 \mathrm{~T}$ for the axial demagnetization at $\theta=315^{\circ}$. Figure 8 shows the magnetic flux density at the center of air-gap and axial direction versus PM volume. It is found that the magnetic flux density is proportional to PM volume irrespective of the direction of demagnetization. Figure 9 shows the calculated magnetic flux density at the center of the air-gap and at $\theta$ $=315^{\circ}$. The magnetic flux density is almost flat in the $z$ direction. Even for axial demagnetization the magnetic flux density is $0.479 \mathrm{~T}$ at $z=0$ and $0.477 \mathrm{~T}$ at $z=42 \mathrm{~mm}$. Figure 10 shows the magnetic flux density at the center of air-gap and $\theta=315^{\circ}$ versus the ratio of PM volume. It is also found that the magnetic flux density is proportional to PM volume irrespective of the direction of demagnetization.

Figure 11 shows the calculated waveform of magnetic flux density at the stator teeth tip. It looks like a rectangular shape. Note that the calculated magnetic flux density for
$R-2.5 \%$ is almost same as that for $z-2.5 \%$. Figure 12 shows its Fourier components. Magnetic flux density for healthy motor includes the fundamental and odds harmonics. On the other hand, magnetic flux density for the motor with demagnetized PMs includes even harmonics and subharmonics as well as the fundamental and odds harmonics. Therefore, if a search coil is installed at the teeth tip of the stator, the magnetization in one of four poles could be detected by the even harmonics and subharmonics of the flux density. There is no difference between the Fourier components of the motor with PMs demagnetized in the radial direction and in the axial direction.

\section{Impedance for High-Frequency Injection}

A high-frequency signal injection has been widely used for the position sensorless control of PMSM, and it was also used PM temperature estimation [10]. This paper investigates high-frequency impedance of PMSM for the diagnosis of very slight PM demagnetization. The impedance was measured 


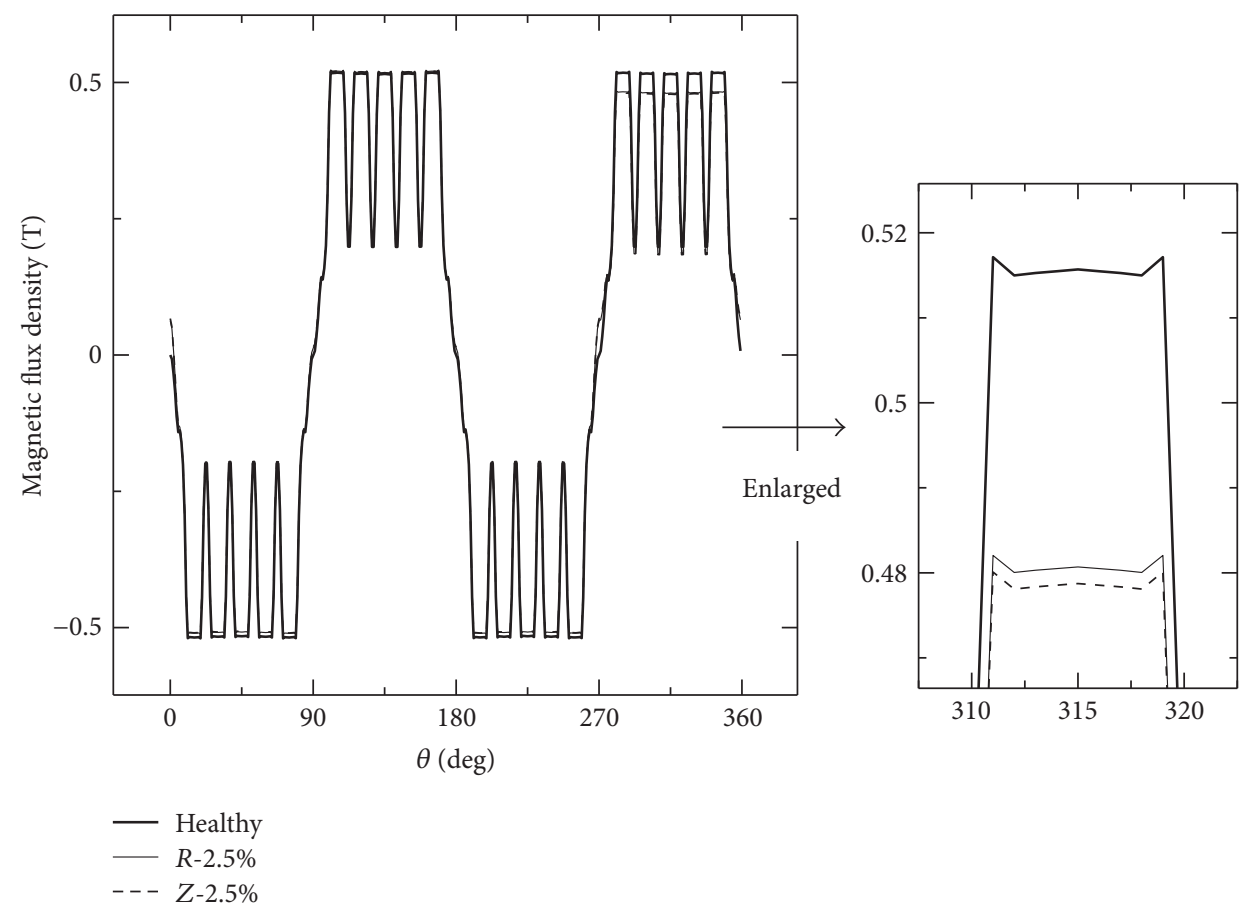

FIgURE 7: Calculated magnetic flux density at the center of the air-gap and axial location $(z=0)$.

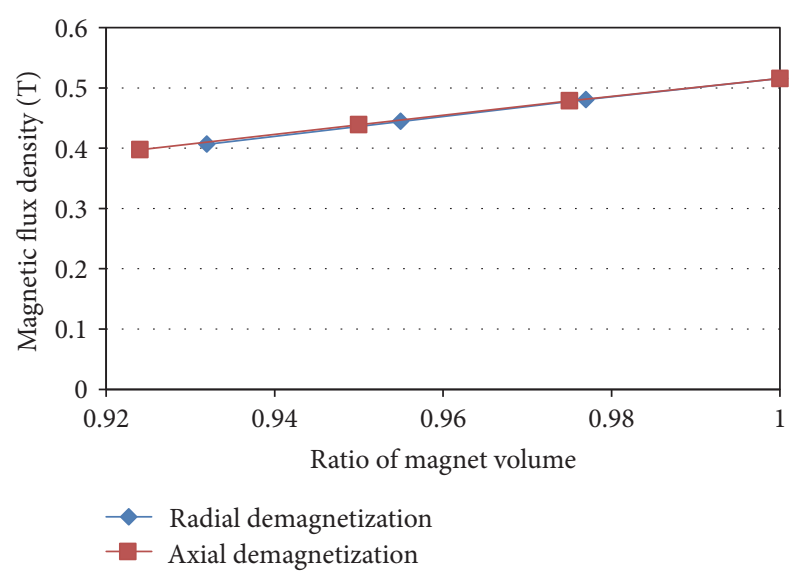

Figure 8: Calculated magnetic flux density at the center point of airgap and axial direction for ratio of PM volume.

when a high-frequency voltage is injected between $u$ and $w$ phases. Here, the motor is not rotating; that is, there is no fundamental voltage and current. Figures 13 and 14 show the measured impedance when the high-frequency voltage of $100 \mathrm{~Hz}$ and $2000 \mathrm{~Hz}$ is injected. The impedance was measured at each rotor position. It is found that the effect of demagnetization strongly appears at the resistance of $100 \mathrm{~Hz}$. In order to show the difference clearly, relative errors of $R$ and $L$ are calculated. Figures 15(a) and 15(b) show the relative error of $L$ when the rotor position is $65 \mathrm{deg}$. and 20 deg., respectively. Figure 16 shows the relative error of resistance $R$. It is found from Figure 15 that the relative error is approximately constant but the value is smaller than the reduction ratio of PM volume. Figure 16 shows that the relative error of resistance $R$ is larger than the reduction ratio of $\mathrm{PM}$ volume in a low frequency region. Therefore, the resistance of low frequency region is useful for the diagnosis of demagnetization of PM. It is shown from Figure 16 that the relative error of resistance at $d$-axis is greater than that at $q$-axis. Reference [10] showed that the PM temperature of surface PM machine can be estimated from the high-frequency resistance. This paper has clarified that the demagnetization of PMs in interior PM machine can be estimated from the relatively low frequency resistance. Moreover, it has been clarified that the resistance at the $d$-axis position is better than that at the $q$-axis position.

\section{Stator Voltage and Current under Vector Control}

One of the authors proposed a simulation model using MATLAB/Simulink as shown in Figure 17 [12]. The model is a typical block diagram for the vector-controlled PMSM system. In this diagram, two control loops are used; one is an inner loop to regulate the stator currents by converting to the $d$ - and $q$-axes with the rotor position, and the other is an outer loop to control the motor speed. The PWM voltage is generated by comparing the voltage reference and a truncated triangular carrier waveform as shown in Figure 17(b). In this block, the stator voltage drop is taken into account by considering an input voltage drop $\Delta V_{\mathrm{dc}}$ and an inverter voltage drop. Figure 18 shows the measured input voltage drop $\Delta V_{\mathrm{dc}}$. This voltage drop can be represented by a linear equation and is represented by a block $V \mathrm{dc} d r o p$ as shown in Figure 17(c). It is well known that the forward 


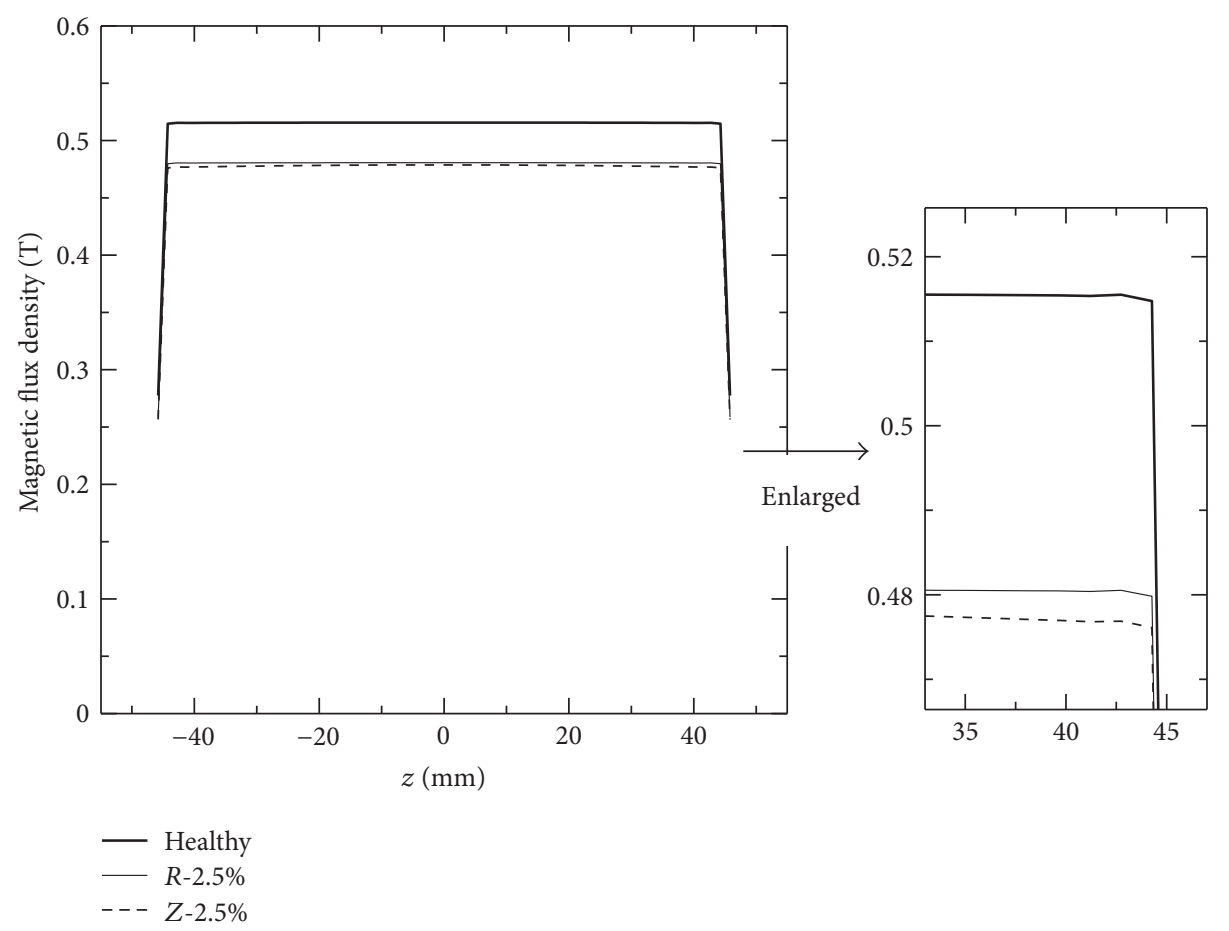

Figure 9: Calculated flux density at the center of the air-gap and $\theta=315^{\circ}$.

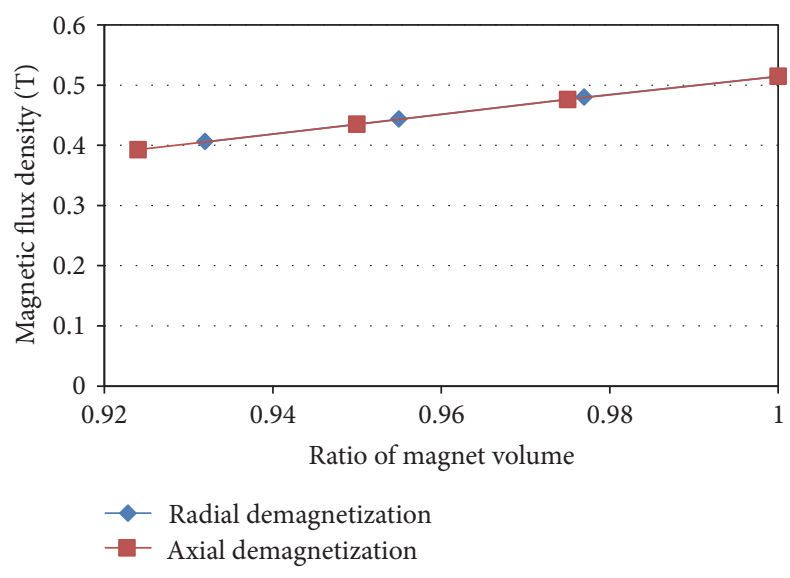

FIGURE 10: Calculated magnetic flux density at the center point of air-gap and $\theta=315^{\circ}$ for ratio of PM volume.

characteristics of the IGBT and diode are nonlinear and vary with temperature. In order to simplify the analysis, this paper assumes that the $v-i$ characteristics of the IGBT and diode are represented by constant forward voltage drops, $v_{-} \operatorname{Tr}$ and $v_{-} D$, respectively, and resistance, $r_{-} \operatorname{Tr}$ and $r_{-} D$, respectively. The inverter situations with positive current and negative current are shown in Figure 19. The letter $s$ denotes a switching function for the transistor. When $s=1$, the gate signal of the upper transistor is turned on, and when $s=0$, the gate signal of the lower transistor is turned on. When $s=1$ and the stator current is positive, the upper transistor is turned on, and then output voltage is shifted down by $v_{-} \operatorname{Tr}+i * r_{-} \operatorname{Tr}$ as shown in case 1. Similarly, when the current is negative,

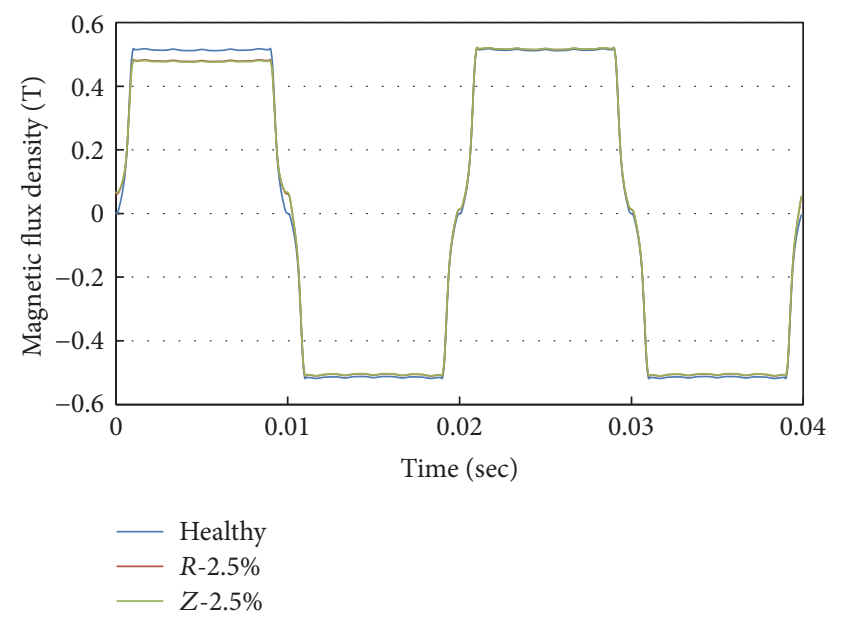

FIGURE 11: Calculated magnetic flux density waveform at the stator teeth tip.

output voltage is shifted up by $v D+i * r_{-} D$ as shown in case 3. Four cases shown in Figure 19 can be represented by a block shown in Figure 17(d). In the simulation block, the IPMSM is modeled in terms of the stator resistance, $d$ and $q$ inductances $L_{d}$ and $L_{q}$, and the flux linkage. In order to evaluate the effect of demagnetization of the PM, the value of the flux linkage is reduced in the simulation. On the contrary, the stator resistance is fixed, and the inductances $L_{d}$ and $L_{q}$ of the demagnetized motor are assumed to be the same as those of a healthy motor, because the difference of inductances from those of healthy machine is very small as shown in Figures 14 and 15. There is no three-phase imbalance of EMF and 


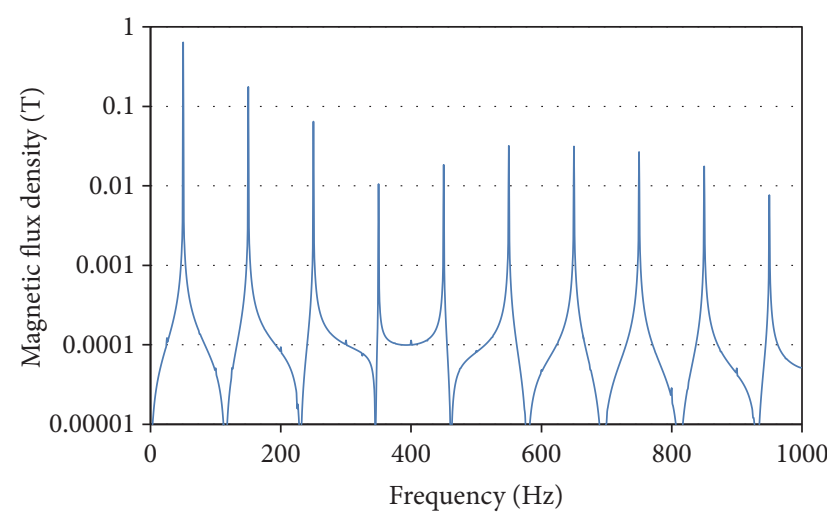

(a) Healthy

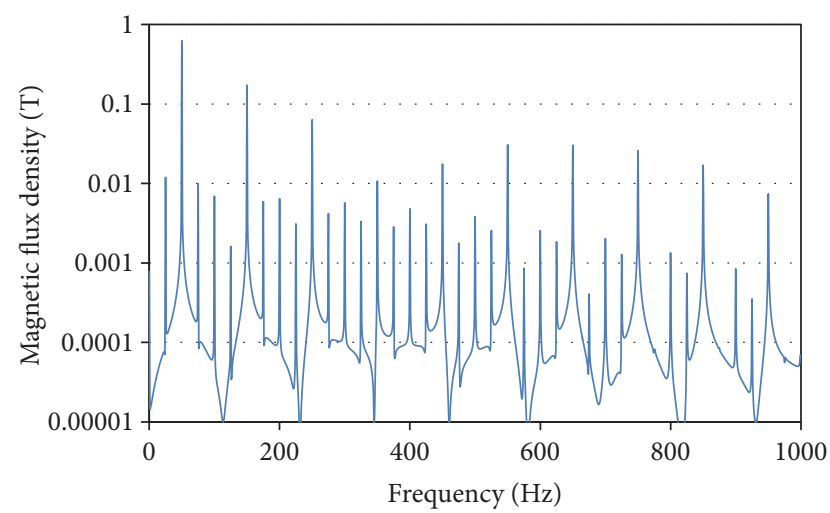

(b) Radial demagnetization

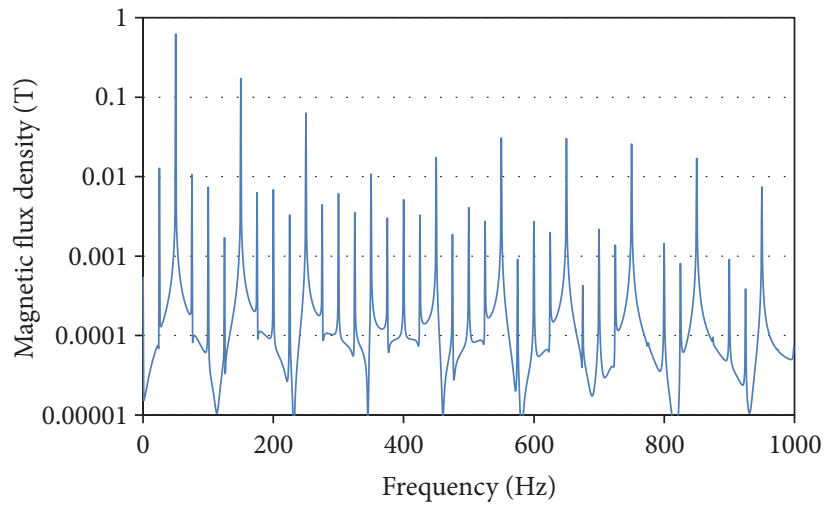

(c) Axial demagnetization

FIGURE 12: Fourier analysis of the magnetic flux density at the stator teeth tip.

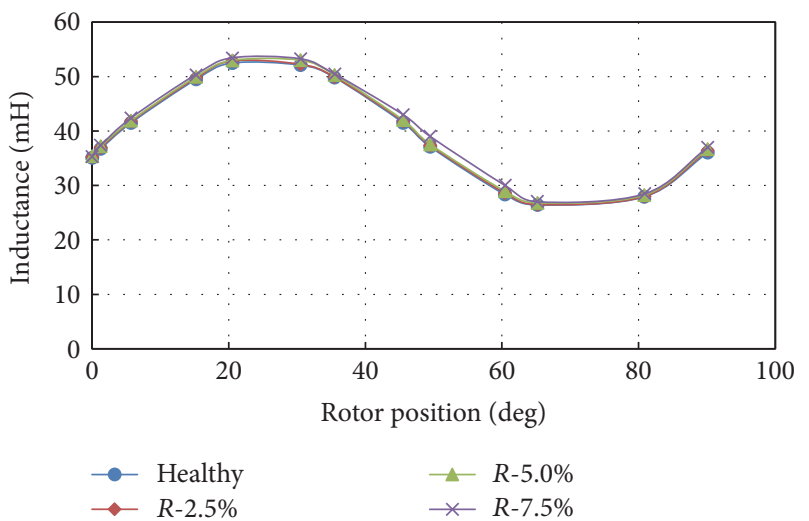

(a) Inductance

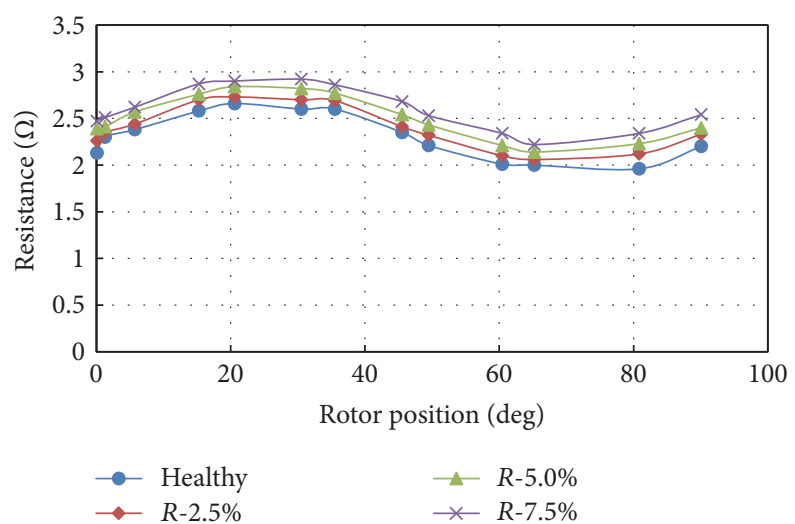

(b) Resistance

Figure 13: Measured impedance between $u$ and $w$ terminal at $100 \mathrm{~Hz}$.

inductances caused by one-pole demagnetization, because the stator windings are connected in series. Although the small vibration and acoustic noise may be produced, this paper assumes they are negligible.

Figure 20(a) shows the fundamental component of the stator current with radial demagnetization. It is shown that the stator current is approximately proportional to the load torque and that the differences due to demagnetization are very small when the load torque is small, and they become large when the load torque becomes large. Figure 20(b) shows the $d$ - and $q$-axis currents $i_{d}$ and $i_{q}$. As $i_{d}$ is controlled to be 0 , the characteristic of $i_{q}$ is equal to the stator current shown in Figure 20(a). Figure 20(c) shows the fundamental component of the stator voltage. It is found that there is a difference due to demagnetization. When the load torque is small, the stator voltage of the motor demagnetized by $7.5 \%$ has the lowest value and that of the healthy motor has the highest value. In contrast, when the load torque is large, the stator 


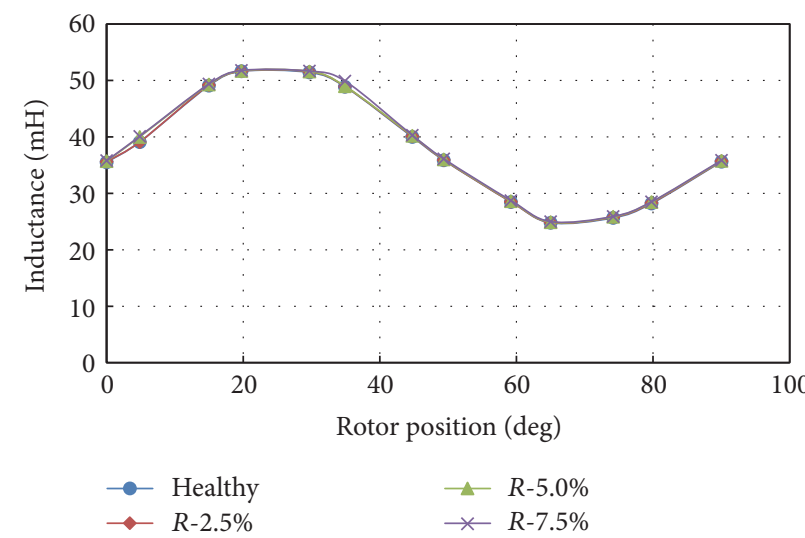

(a) Inductance

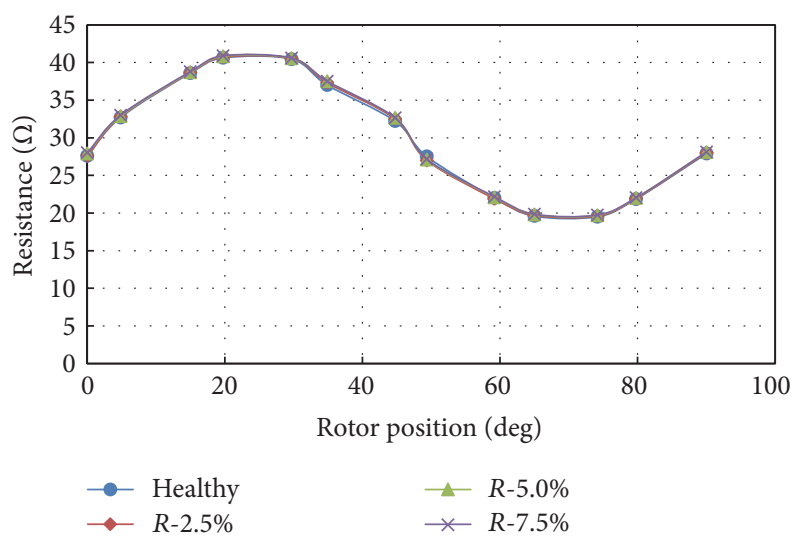

(b) Resistance

FIgURE 14: Measured impedance between $u$ and $w$ terminal at $2000 \mathrm{~Hz}$.

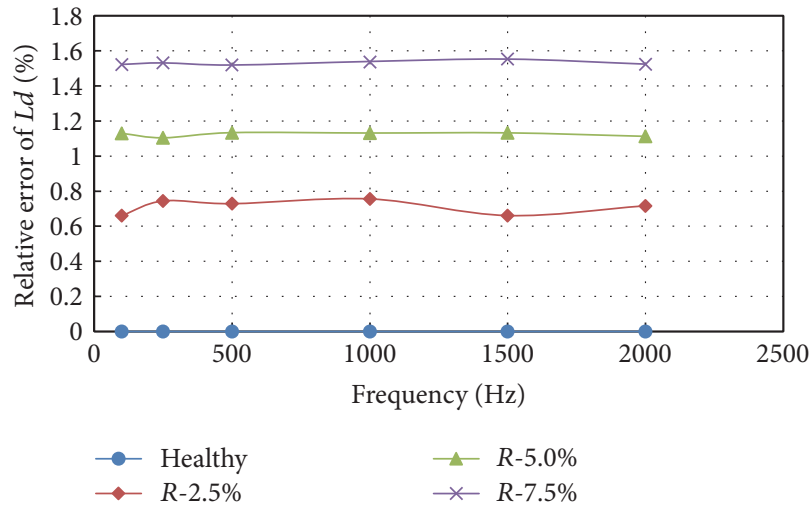

(a) At $d$-axis

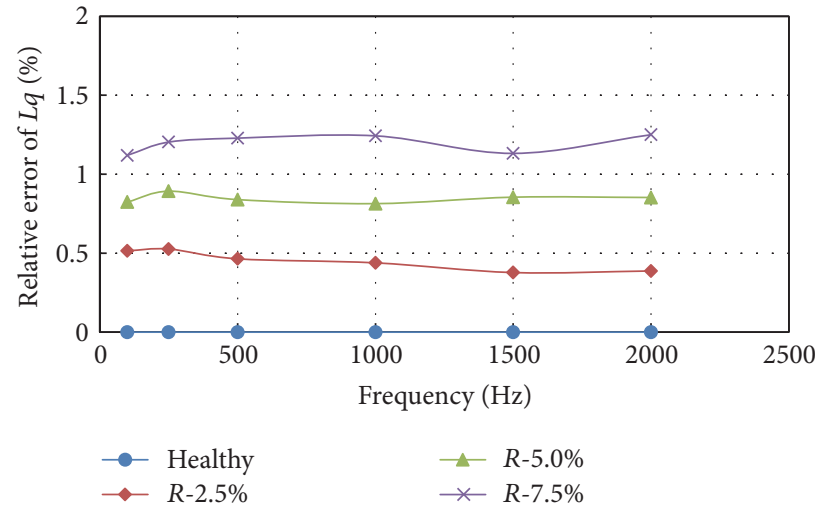

(b) At $q$-axis

FIGURE 15: Relative error of measured inductance.

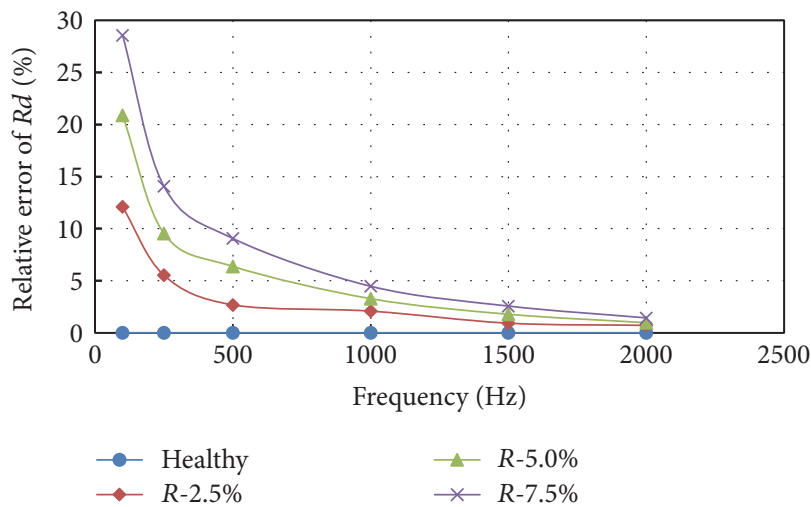

(a) At $d$-axis

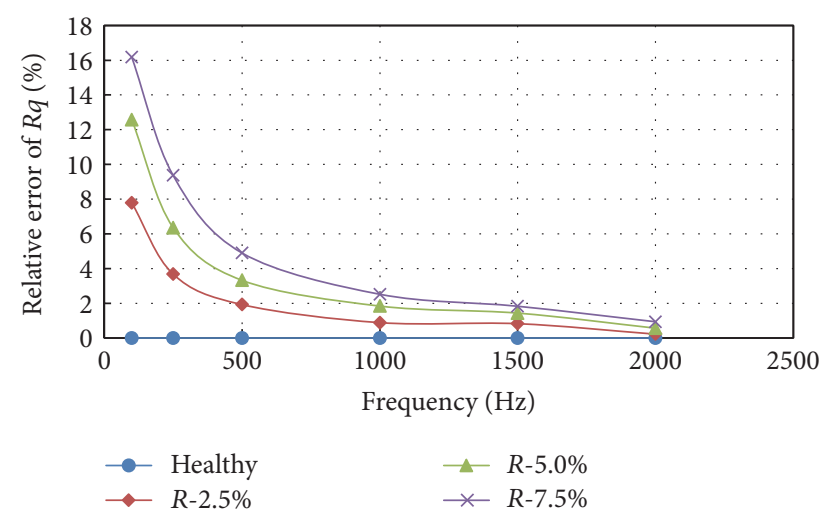

(b) At $q$-axis

FIGURE 16: Relative error of measured resistance.

voltage of the motor demagnetized by $7.5 \%$ has the highest value. The stator voltage and current of the motor with axial demagnetization are the same as those shown in Figure 20.

Experimental conditions are $0 \%, 10 \%, 20 \%$, and $30 \%$ of rated torque and a speed of $1500 \mathrm{~min}^{-1}$. Figure 21 shows the fundamental component of the stator current and stator voltage of the IPMSM with radial demagnetization. The fundamental component of the stator current becomes large when the load torque becomes large. When the load torque is small, the stator voltage of the motor demagnetized by $7.5 \%$ has the lowest value and that of the healthy motor has the highest value. In contrast, when the load torque 


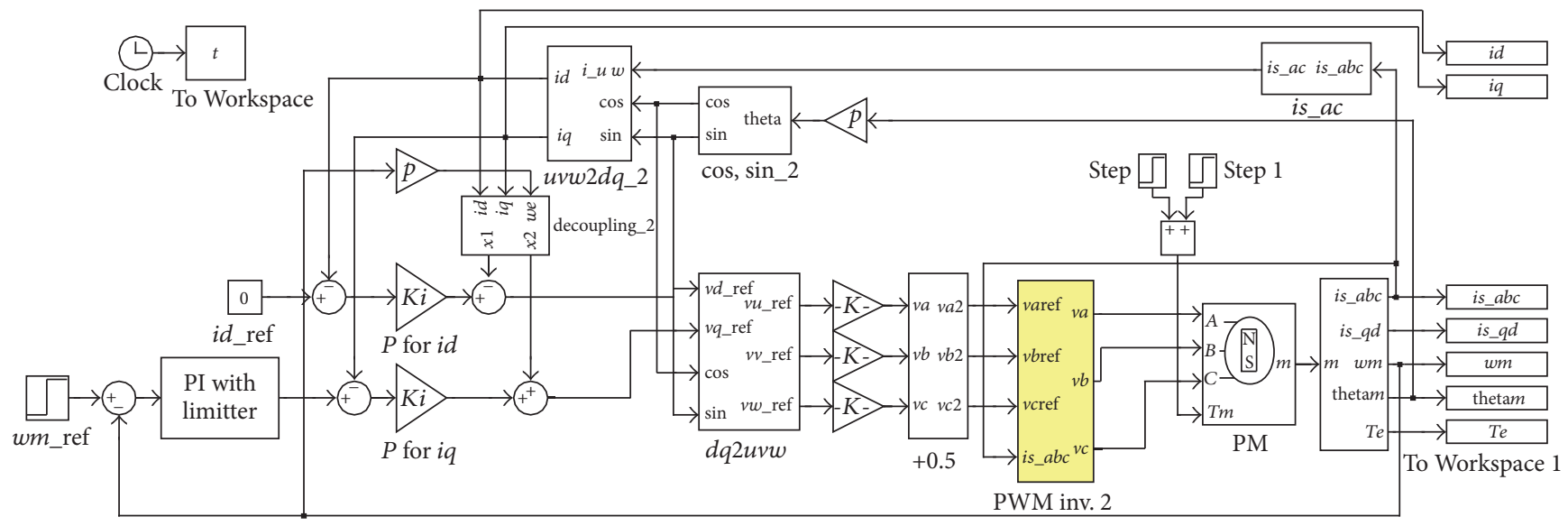

(a) Whole system

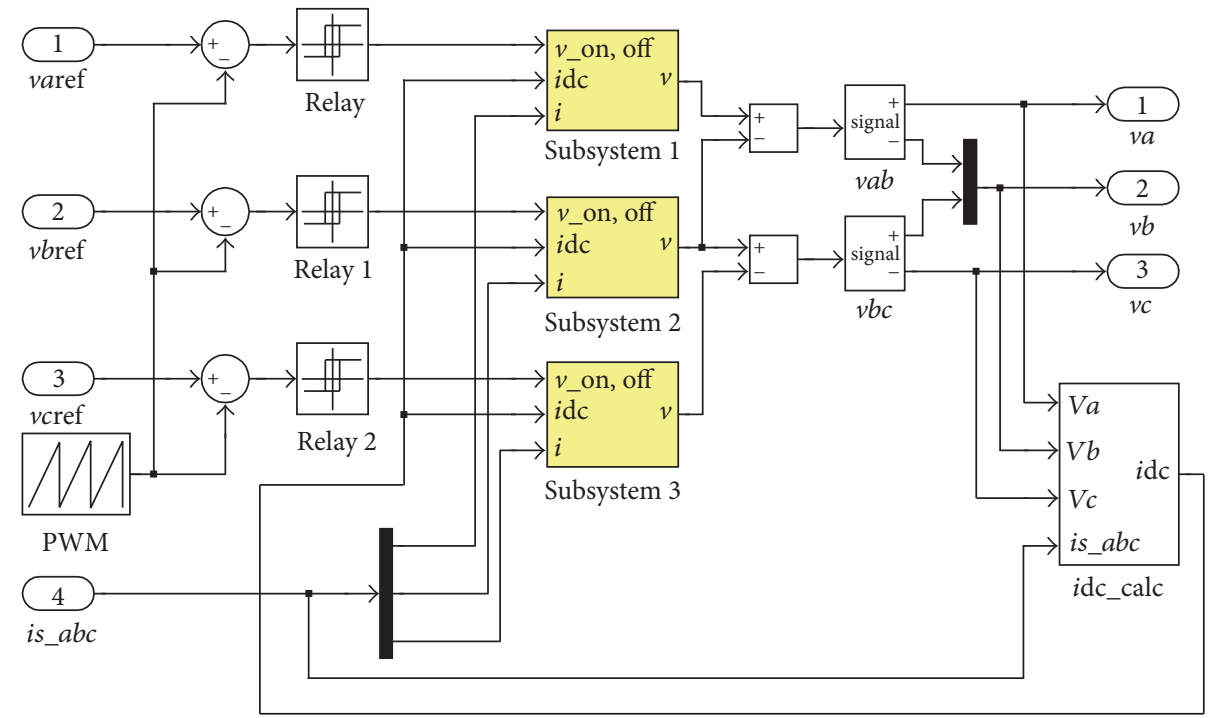

(b) Subsystem for PWM inv in (a)

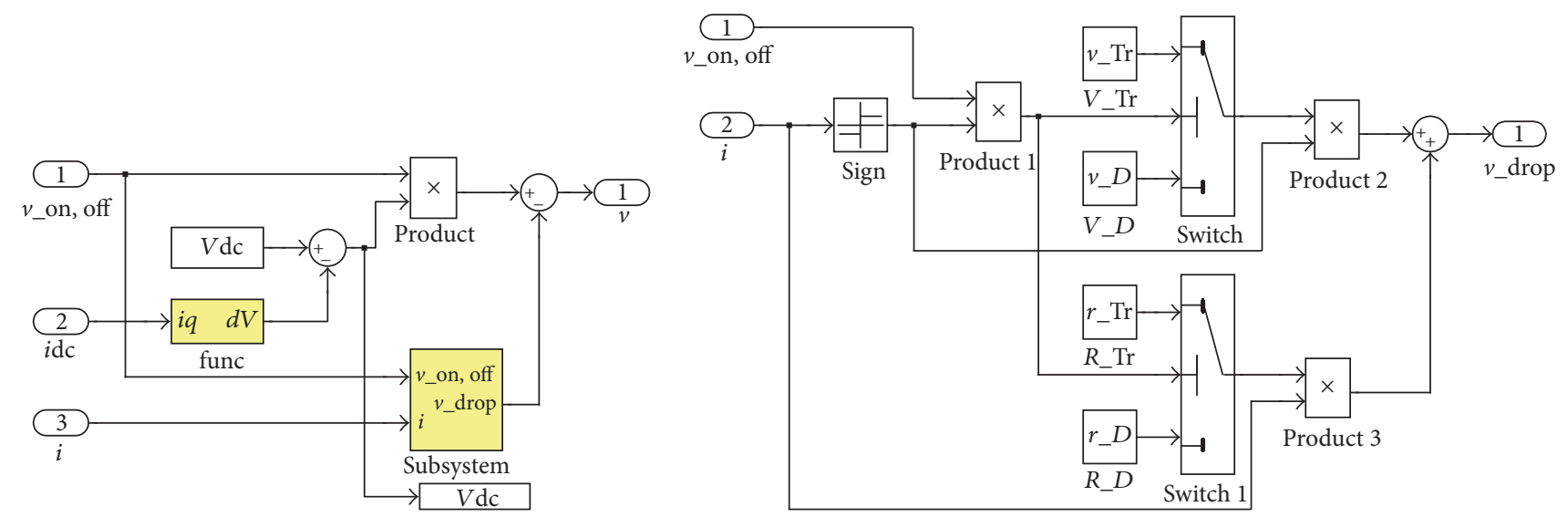

(c) Subsystem for $v a, v b$, and $v c$ in (b)

(d) Subsystem voltage drop in (c)

FIGURE 17: Block diagram for a brushless DC motor controlled using the vector control strategy. 


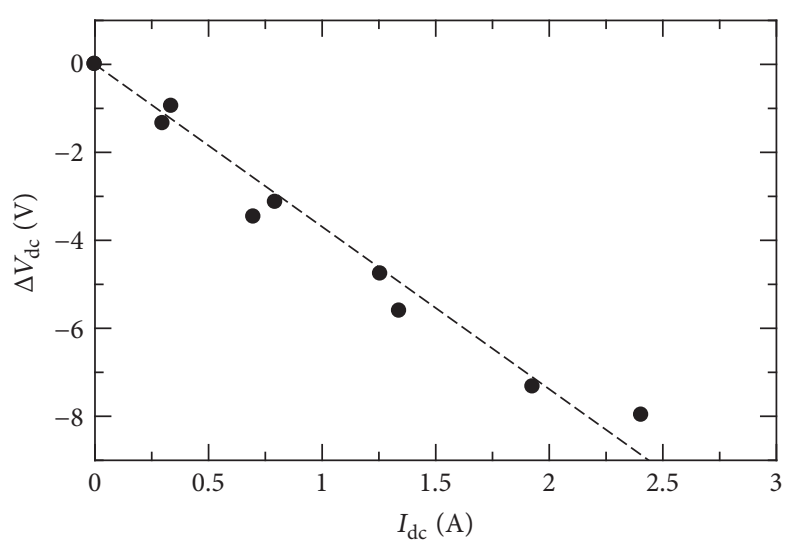

FIGURE 18: DC voltage drop across the inverter.

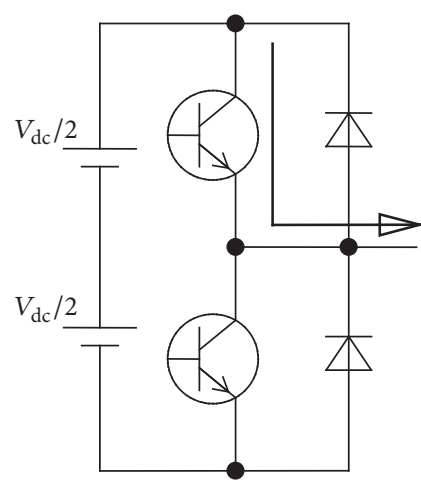

Case 1: $s=1, i>0$

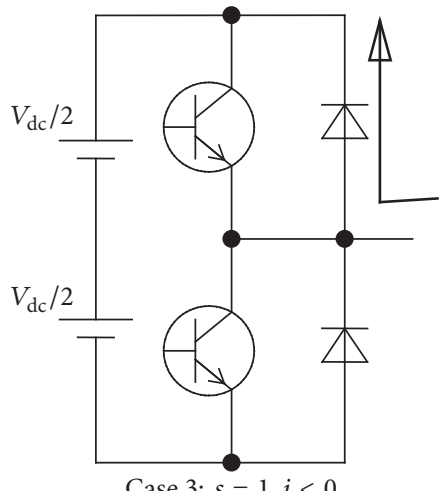

Case 3: $s=1, i<0$

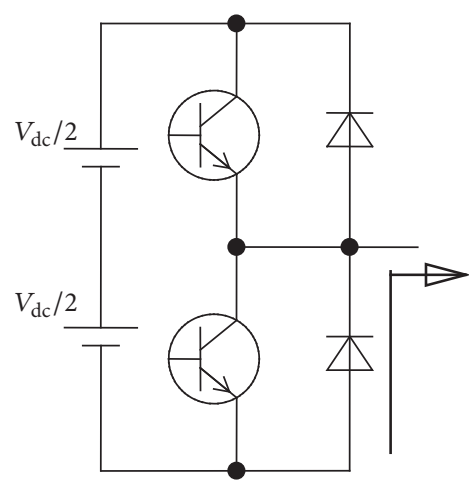

Case 2: $s=0, i>0$

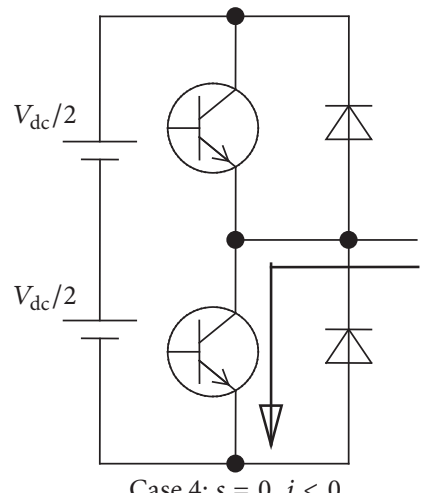

Case 4: $s=0, i<0$

Figure 19: Analysis of the output voltage of a phase inverter leg.

is large, the stator voltage of the motor demagnetized by $7.5 \%$ has the highest value. These results are approximately the same as those shown in Figure 20. The measured stator voltage and current of the motor with axial demagnetization were also approximately the same as the simulation results shown in Figure 20. We think that the differences between the simulation results and the measured ones are due to the following assumptions. The simulation block diagram shown in Figure 17 uses permanent magnet synchronous machine model $P M$ provided in SimPowerSystem toolbox of MATLAB/Simulink. Therefore the space harmonics are ignored in this mode. Although the actual inductances
$L_{d}$ and $L_{q}$ change according to the value of stator current, they are assumed to be constant. However, since the simulation results are approximately same as the measured ones, the simulation results have been experimentally verified.

Here, we will discuss these characteristics. When $i_{d}$ is controlled to be 0 , the voltage and torque equations are expressed by

$$
\begin{aligned}
& v_{d}=-\omega L_{q} i_{q}, \\
& v_{q}=\left(R+P L_{q}\right) i_{q}+\omega \phi,
\end{aligned}
$$




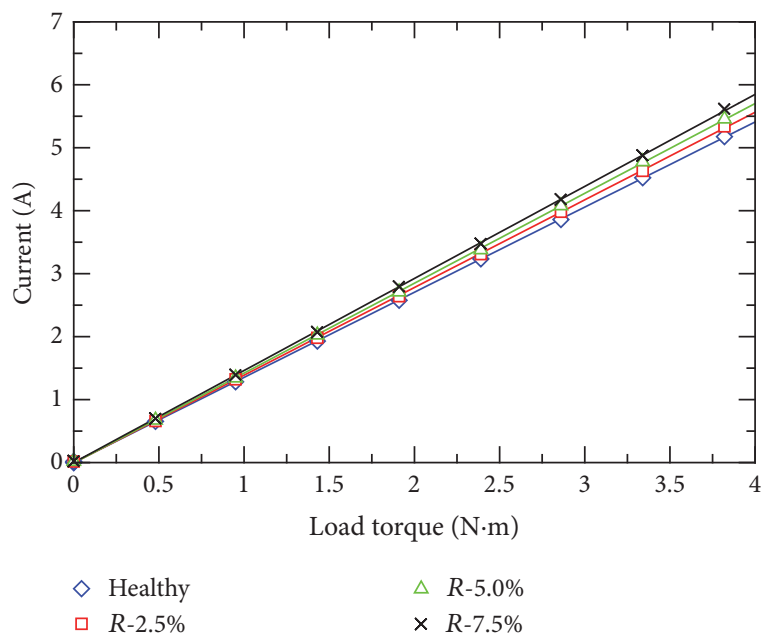

(a) Fundamental component of the stator current

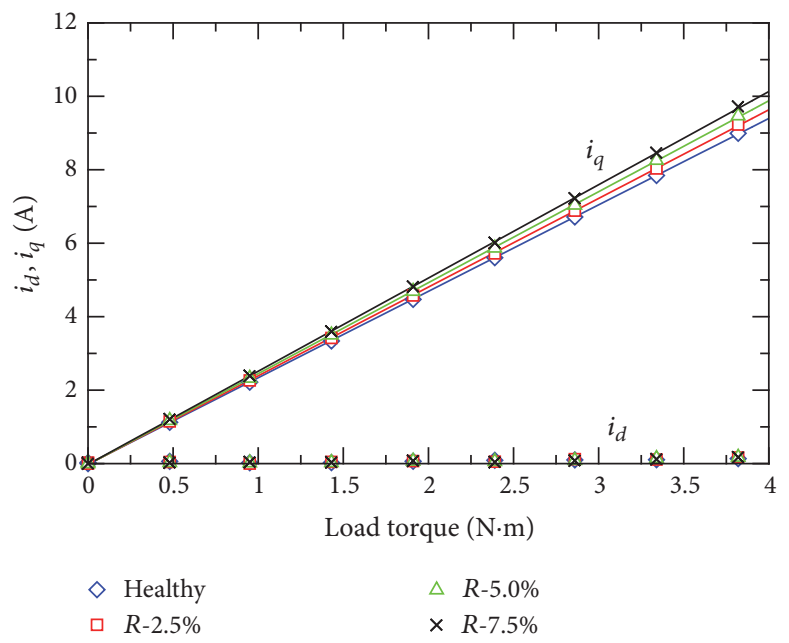

(b) Stator currents $i_{d}, i_{q}$

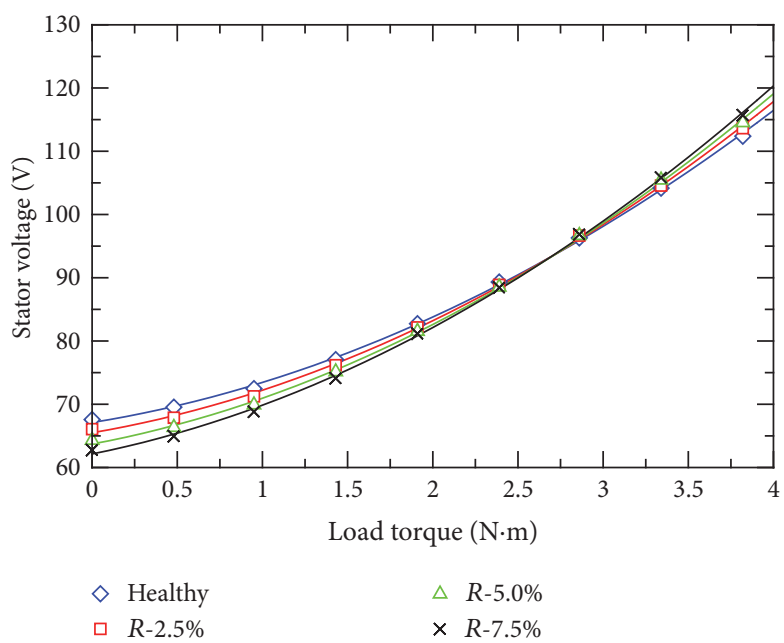

(c) Fundamental component of the stator voltage

Figure 20: Simulated results using vector control.

$$
T=p \phi i_{q}
$$

where $v_{d}, v_{q}, \omega, \phi, P$, and $p$ are $d$-axis voltage, $q$-axis voltage, angular velocity, flux linkage, differential operator, and pole pairs, respectively. From (3), as $i_{q}$ is inversely proportional to flux linkage $\phi, i_{q}$ of the demagnetized motor is large when the load torque is large, as shown in Figure 20(a). And the flux linkage is proportional to the magnet volume, that is, demagnetization situation. Therefore, the demagnetization of PM can be estimated by the stator current under vector control with $i_{d}=0$. Note that a variation of the stator resistance due to stator temperature variation produces the same effect.

From (1) and (2), $v_{q}$ is proportional to $\omega \phi$ and $v_{d}$ becomes 0 , when the load torque is small; that is, $i_{q}$ is small. In contrast, when the load torque becomes large, that is, $i_{q}$ becomes large, $v_{q}$ is affected by $i_{q}$ as shown in (2). As a result, the stator voltage of the demagnetized motor becomes large, as shown in Figure 20(c). The torque at the intersection point is driven as

$$
T=\frac{p \omega \Phi_{\text {healthy }} \Phi_{\text {faulty }}}{\sqrt{\omega^{2} L_{q}{ }^{2}+R^{2}}},
$$

where $\Phi_{\text {healthy }}$ and $\Phi_{\text {faulty }}$ are the flux linkages of healthy motor and demagnetized motor, respectively. Here it is assumed that $R$ and $L_{q}$ do not change by the demagnetization. Therefore, since $v_{q}$ is proportional to $\omega \phi$ when $i_{q}=0$ at no load, the stator voltage at no load is useful for the diagnosis of demagnetization.

\section{Conclusions}

This paper has investigated the diagnosis of very slight PM demagnetization by both simulations and experiments. The reduction of the flux linkage, that is, back-EMF of the motor with demagnetized PMs, is equal to the reduction of PM volume, and there is no difference in the demagnetization in the radial direction and in the axial direction. Magnetic flux density at the teeth tip of the motor with demagnetized PMs includes even harmonics and subharmonics as well as 


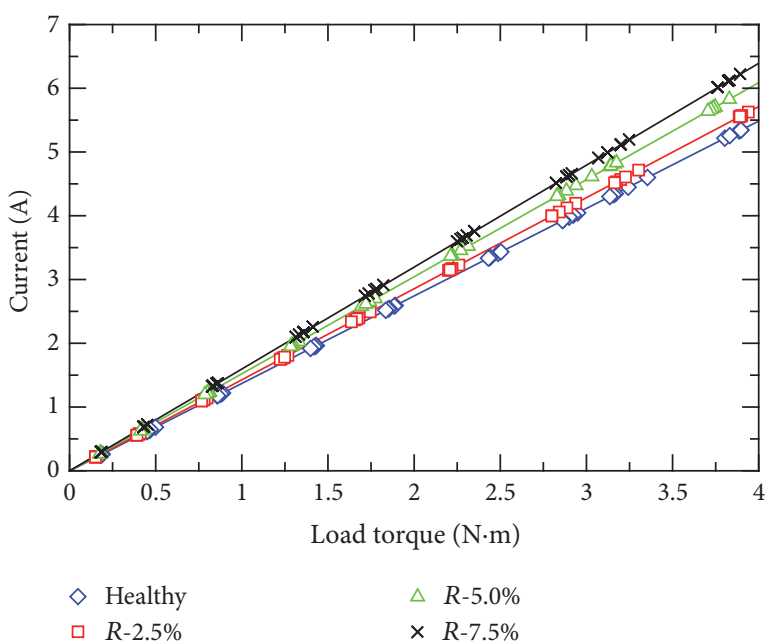

(a) Fundamental component of the stator current

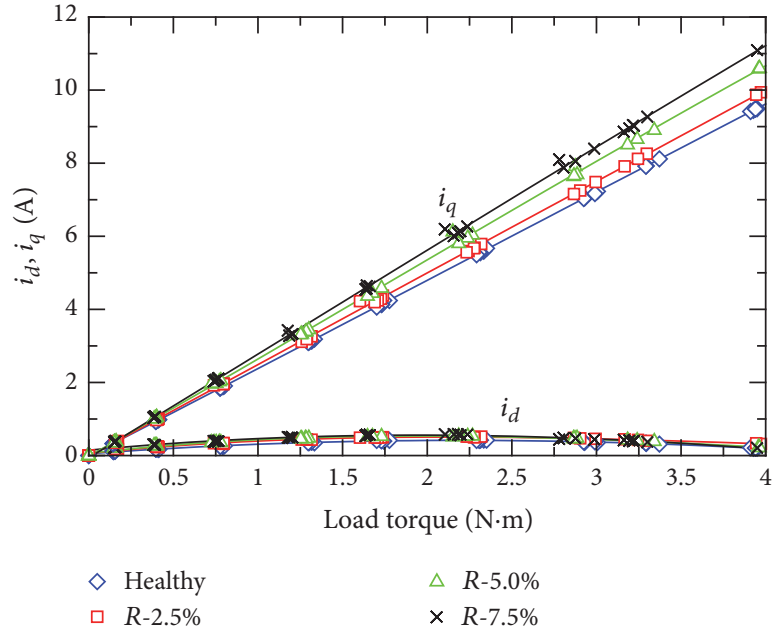

(b) Stator currents $i_{d}, i_{q}$

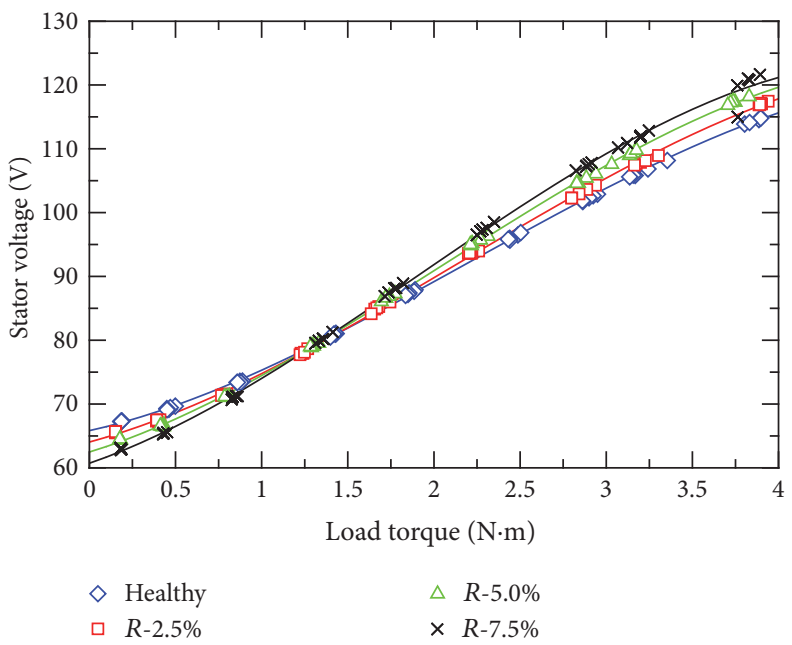

(c) Fundamental component of the stator voltage

FIGURE 21: Measurement results under vector control.

the fundamental and odds harmonics. The demagnetization of PMs in interior PM machine can be estimated from the relatively low frequency resistance, and the resistance at the $d$-axis position is better than that at the $q$-axis position for diagnosis. Under vector control, the stator voltage is useful except in an intermediate torque range, and the intermediate torque is expressed by a simple equation.

\section{Conflicts of Interest}

The authors declare that there are no conflicts of interest regarding the publication of this paper.

\section{References}

[1] J.-C. Urresty, J.-R. Riba, M. Delgado, and L. Romeral, "Detection of demagnetization faults in surface-mounted permanent magnet synchronous motors by means of the zero-sequence voltage component," IEEE Transactions on Energy Conversion, vol. 27, no. 1, pp. 42-51, 2012.
[2] S. Rajagopalan, R. W. Le, T. G. Habetler, and R. G. Harley, "Diagnosis of potential rotor faults in brushless DC machines," in Proceedings of the Second IEE International Conference on Power Electronics, Machines and Drives, vol. 2, pp. 668-673, Edinburgh, UK, 2004.

[3] A. G. Espinosa, J. A. Rosero, J. Cusidó, L. Romeral, and J. A. Ortega, "Fault detection by means of Hilbert-Huang transform of the stator current in a PMSM with demagnetization," IEEE Transactions on Energy Conversion, vol. 25, no. 2, pp. 312-318, 2010.

[4] M. D. Prieto, A. G. Espinosa, J.-R. Riba Ruiz, J. C. Urresty, and J. A. Ortega, "Feature Extraction of demagnetization faults in permanent-magnet synchronous motors based on boxcounting fractal dimension," IEEE Transactions on Industrial Electronics, vol. 58, no. 5, pp. 1594-1605, 2011.

[5] J.-C. Urresty, J.-R. Riba, and L. Romeral, "A back-emf based method to detect magnet failures in PMSMs," IEEE Transactions on Magnetics, vol. 49, no. 1, pp. 591-598, 2013.

[6] K. Liu and Z. Q. Zhu, "Online estimation of the rotor flux linkage and voltage-source inverter nonlinearity in permanent 
magnet synchronous machine drives," IEEE Transactions on Power Electronics, vol. 29, no. 1, pp. 418-427, 2014.

[7] O. Wallscheid, T. Huber, W. Peters, and J. Bocker, "Realtime capable methods to determine the magnet temperature of permanent magnet synchronous motors - A review," in Proceedings of the Industrial Electronics Society, IECON 2014 40th Annual Conference of the IEEE, pp. 811-818, Dallas, Tex, USA, November 2014

[8] A. Specht, O. Wallscheid, and J. Bocker, "Determination of rotor temperature for an interior permanent magnet synchronous machine using a precise flux observer," in Proceedings of the 7th International Power Electronics Conference, IPEC-Hiroshima ECCE Asia 2014, pp. 1501-1507, Hiroshima, Japan, May 2014.

[9] M. Ganchev, C. Kral, H. Oberguggenberger, and T. Wolbank, "Sensorless rotor temperature estimation of permanent magnet synchronous motor," in Proceedings of the 37th Annual Conference of the IEEE Industrial Electronics Society, IECON 2011, pp. 2018-2023, Melbourne, VIC, Australia, November 2011.

[10] D. D. Reigosa, F. Briz, P. García, J. M. Guerrero, and M. W. Degner, "Magnet temperature estimation in surface PM machines using high-frequency signal injection," IEEE Transactions on Industry Applications, vol. 46, no. 4, pp. 1468-1475, 2010.

[11] S. Shinagawa, T. Ishikawa, and N. Kurita, "Characteristics of interior permanent magnet synchronous motor with imperfect magnets," in Proceedings of the 7th International Power Electronics Conference, IPEC-Hiroshima - ECCE Asia 2014, pp. 252-257, Hiroshima, Japan, May 2014.

[12] T. Ishikawa, T. Iida, and M. Matsunami, "Analysis of Brushless DC Motor by Simulink and FEM Considering DC Voltage Drop and Inverter Properties," Journal of the Japan Society of Applied Electromagnetics and Mechanics, vol. 17, pp. 77-80, 2009. 


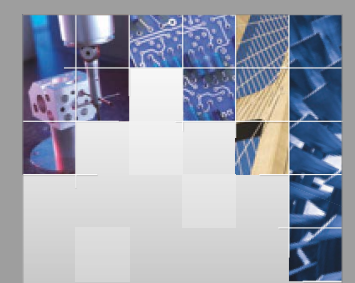

\section{Enfincering}
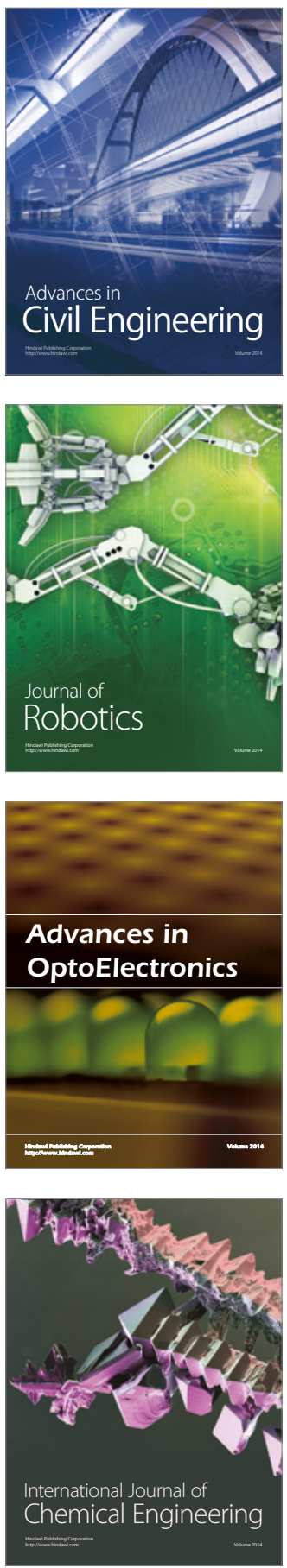

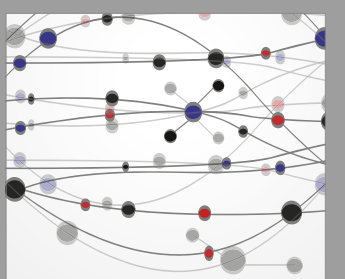

The Scientific World Journal

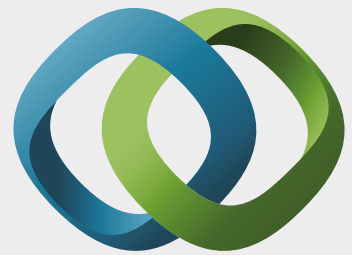

\section{Hindawi}

Submit your manuscripts at

https://www.hindawi.com
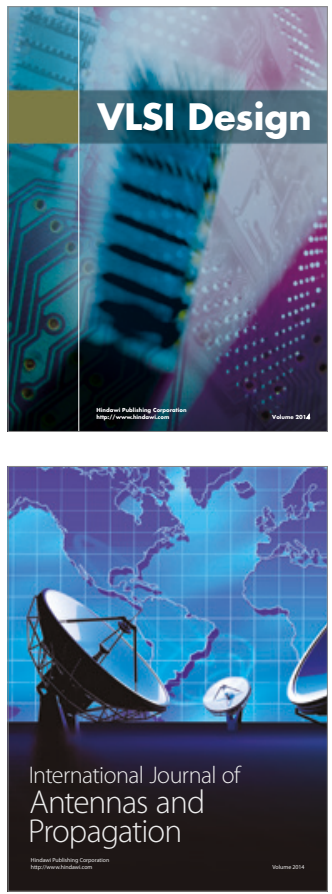

\section{Rotating}

Machinery
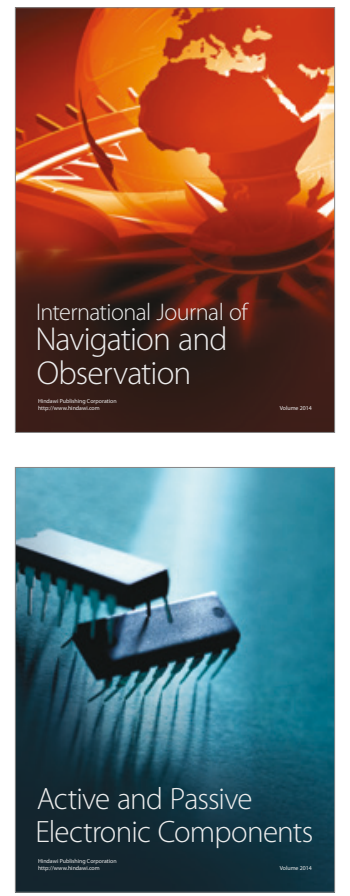
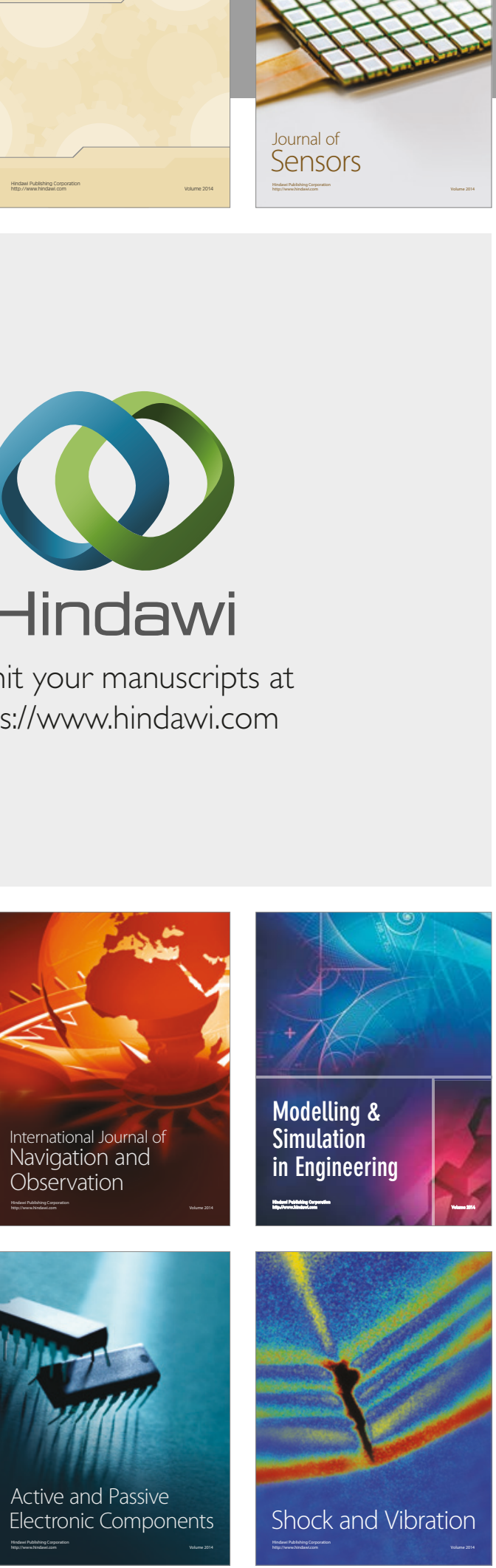
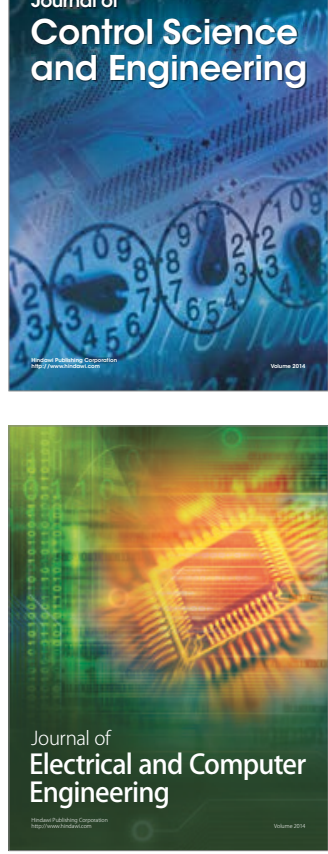

Distributed

Journal of

Control Science

and Engineering
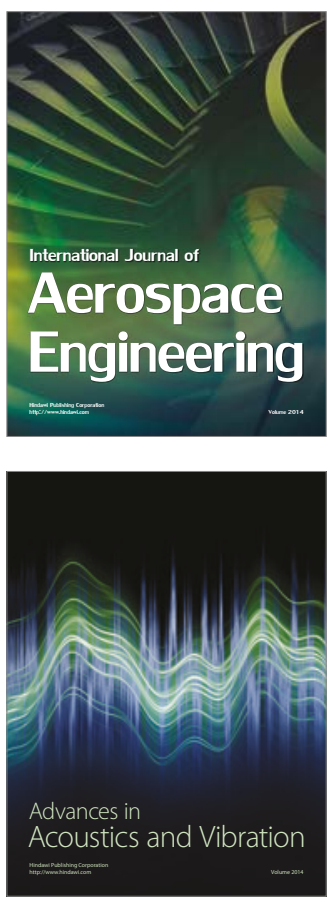

Sensor Networks 